\title{
A family 26 mannanase produced by Clostridium thermocellum as a component of the cellulosome contains a domain which is conserved in mannanases from anaerobic fungi
}

\author{
Jonathan R. Halstead, ${ }^{1}$ Philip E. Vercoe, ${ }^{2}$ Harry J. Gilbert, ${ }^{3}$ \\ Keith Davidson ${ }^{1}$ and Geoffrey P. Hazlewood ${ }^{1}$
}

Author for correspondence: Harry J. Gilbert. Tel: +44 191 2226609. Fax: +44 1912228684.

e-mail: h.j.gilbert@newcastle.ac.uk

1 Laboratory of Molecular Enzymology, The Babraham Institute, Babraham, Cambridge CB2 4AT, UK

2 Department of Animal Science, University of Western Australia, Nedlands, WA 6009, Australia

3 Department of Biological and Nutritional Sciences, The University of Newcastle upon Tyne, Newcastle upon Tyne NE1 7RU, UK

\begin{abstract}
Cellulosomes prepared by the cellulose affinity digestion method from Clostridium thermocellum culture supernatant hydrolysed carob galactomannan during incubation at $60^{\circ} \mathrm{C}$ and pH 6.5. A recombinant phage expressing mannanase activity was isolated from a library of $C$. thermocellum genomic DNA constructed in $\lambda Z A P I I$. The cloned fragment of DNA containing a putative mannanase gene (manA) was sequenced, revealing an ORF of $1767 \mathrm{nt}$, encoding a protein (mannanase A; Man26A) of 589 aa with a molecular mass of $66816 \mathrm{Da}$. The putative catalytic domain (CD) of Man26A, identified by gene sectioning and sequence comparisons, displayed up to $32 \%$ identity with other mannanases belonging to family 26 . Immediately downstream of the CD and separated from it by a short proline/threonine linker was a duplicated 24residue dockerin motif, which is conserved in all $C$. thermocellum cellulosomal enzymes described thus far and mediates their attachment to the cellulosomeintegrating protein (CipA). Man26A consisting of the CD alone (Man26A') was hyperexpressed in Escherichia coli BL21(DE3) and purified. The truncated enzyme hydrolysed soluble and insoluble mannan, displaying a temperature optimum of $65^{\circ} \mathrm{C}$ and a pH optimum of 6.5, but exhibited no activity against other plant cell wall polysaccharides. Antiserum raised against Man26A' crossreacted with a polypeptide with a molecular mass of $70000 \mathrm{Da}$ that is part of the $C$. thermocellum cellulosome. A second variant of Man26A containing the $\mathbf{N}$-terminal segment of 130 residues and the CD (Man26A") bound to ivory-nut mannan and weakly to soluble Carob galactomannan and insoluble cellulose. Man26A' consisting of the CD alone did not bind to these polysaccharides. These results indicate that the $\mathbf{N}$-terminal 130 residues of mature Man26A may constitute a weak mannan-binding domain. Sequence comparisons revealed a lack of identity between this region of Man26A and other polysaccharidebinding domains, but significant identity with a region conserved in the three family 26 mannanases from the anaerobic fungus Piromyces equi.
\end{abstract}

Keywords: mannanase, Clostridium thermocellum, cellulosome, family 26

\section{INTRODUCTION}

Some of the most active cellulase/hemicellulase systems known are produced by anaerobic bacteria, notably

Abbreviations: $C B D$, cellulose-binding domain; $C D$, catalytic domain. The GenBank/EMBL accession number for the sequence reported in this paper is AJ242666. clostridia, and consist of multiple catalytic subunits organized into high-molecular-mass complexes. The paradigm for such systems is the extracellular cellulosome complex produced by the anaerobic thermophile Clostridium thermocellum (Lamed \& Bayer, 1988). A key component of the cellulosome is the non-catalytic scaffolding protein, or cellulosome-integrating protein (CipA) containing nine homologous receptors of about 
150 residues (cohesins) to which catalytic subunits bind via a conserved docking domain or dockerin of 24 reiterated residues. A tenth domain in CipA functions as a cellulose-binding domain (CBD; family III), mediating strong binding of the complex to cellulosic substrates (Tormo et al., 1996).

Enzymes active in the degradation of cellulose (endoglucanases, exoglucanases and $\beta$-glucosidases) account for the majority of cellulosomal subunits, but several highly active thermostable xylanases are also present, even though C. thermocellum is unable to utilize xylose as a source of fermentable carbon (Wiegel et al., 1985). One possible explanation for this is that efficient utilization of the plant cell wall as a substrate for microbial growth necessitates the hydrolysis of not only cellulose, but a range of hemicellulosic polysaccharides which contribute to the structural complexity of the cell wall and could prevent cellulases from reaching their target substrate.

To test this theory, we have examined the capacity of $C$. thermocellum to hydrolyse mannan, a polysaccharide that is found in significant quantity in the hemicellulose fraction from softwoods, the seeds of leguminous plants and a variety of nuts and beans. The simplest mannan is a linear homopolymer of $\beta$-1,4-linked mannose residues (Puls \& Schuseil, 1993). Galactomannan has a similar backbone, but is substituted with $\alpha-1,6$-linked galactose side-chains, while in glucomannans, $\beta-1,4$-glucose residues are interspersed through the backbone, which can be substituted with $\alpha-1,6$-galactoses. Substitution with $\mathrm{O}$-acetyl groups at the C-2 and C-3 positions of mannose is common for all mannans.

Enzymic depolymerization of the mannan backbone is effected by endo- $\beta$-1,4-mannanases which cleave randomly within the chain, producing mannobiose and longer manno-oligosaccharides from which mannose is released by exo-acting $\beta$-mannosidases. In addition, $\alpha$ galactosidase and $\beta$-glucosidase are required for the complete breakdown of galactoglucomannan. The most intensively studied member of this enzyme consortium is endomannanase (mannanase). To date, primary sequences have been reported for 10 mannanases from bacteria and fungi. Based on sequence alignments and hydrophobic cluster analysis, all known mannanase catalytic domains (CDs) can be attributed to two distinct glycosyl hydrolase families, namely families 5 and 26 . Interestingly, both enzyme families contain cellulases, although the mannanases analysed to date have narrow substrate ranges and do not exhibit significant activity against cellulose.

In this paper we show that C. thermocellum has the capacity to depolymerize mannan and we describe the biochemical properties and molecular architecture of a thermostable mannanase that is part of the cellulosome complex. Sectioning of the mannanase gene coupled with functional analysis of the truncated gene products and primary sequence comparisons reveal that the enzyme contains a family $26 \mathrm{CD}$, a domain that binds mannan weakly which is conserved in mannanases from anaerobic fungi and the ubiquitous dockerin that is characteristic of all C. thermocellum cellulosomal subunits.

\section{METHODS}

Microbial strains, vectors and culture conditions. C. thermocellum strain YS was cultured under anaerobic conditions in medium (Kemp et al., 1984) containing cellobiose $(0.5 \%, \mathrm{w} / \mathrm{v})$ at $60^{\circ} \mathrm{C}$. Escherichia coli strains XL-1 Blue (Stratagene) and BL21(DE3) (Novagen) were cultured in Luria-Bertani (LB) broth. Ampicillin $\left(50\right.$ or $\left.100 \mu \mathrm{g} \mathrm{ml}^{-1}\right)$ was added as appropriate to select transformants. Plasmid vectors used were pBluescript SK - (Stratagene), pET32a (Novagen) and pMTL6000.

Construction and screening of gene library. C. thermocellum genomic DNA, prepared as described previously (Romaniec et al., 1987), was partially digested with $M b o I$ and DNA in the size range 3-9 kb was purified by agarose gel electrophoresis and ligated into Xhol-cleaved 2 ZAPII (Stratagene) using the partial fill-in technique described in the supplier's protocol. The DNA was packaged in vitro and infected into E. coli XLIBlue to generate approximately $10^{6}$ recombinant phage. To screen the library for mannanase-producing clones, phage were plated out on NZY top agarose supplemented with $0 \cdot 2 \%$ azo carob galactomannan (Megazyme).

After incubation at $37^{\circ} \mathrm{C}$ for $16 \mathrm{~h}$, mannanase-synthesizing phage were evident by the appearance of clear haloes against a blue background. Clostridial DNA from mannanase-positive phage was excised and recircularized to form phagemid (pBluescript SK - ) as described previously (Black et al., 1994).

General recombinant DNA methodology. Agarose-gel electrophoresis, Southern hybridization, transformation of E. coli and the use of restriction enzymes and T4 DNA ligase were as described by Gilbert et al. (1987). Plasmid DNA was prepared using Qiagen columns. To sequence manA, nested deletions of appropriate restriction fragments were generated using the Exonuclease III/S1-nuclease method. DNA sequencing was carried out using an ABI 373 automated DNA sequencer, in conjunction with the PRISM dye-deoxy termination sequencing kit (Applied Biosystems). Custom-made primers were used where necessary to complete the sequences of both strands.

High-level expression and purification of mannanase A (Man26A). The region of the manA gene encoding the CD of Man26A (Man26A') or the CD and the N-terminal 130 residues of mature Man26A (Man26A") were amplified using primers containing the appropriate restriction sites at the $5^{\prime}$ and $3^{\prime}$ ends, respectively. The reaction $(100 \mu \mathrm{l})$ contained $50 \mathrm{mM}$ Tris/HCl buffer, pH 9.0, $50 \mathrm{mM} \mathrm{NaCl}, 10 \mathrm{mM}$ $\mathrm{MgCl}_{2}, 200 \mu \mathrm{M}$ dNTPs, 50 pmol each primer, $250 \mathrm{ng}$ template DNA (pJH1) and 2 units Taq DNA polymerase (MBI Fermentas). After overlaying with mineral oil, the reaction was subjected to 20 cycles of $30 \mathrm{~s}$ at $94^{\circ} \mathrm{C}, 45 \mathrm{~s}$ at $45^{\circ} \mathrm{C}$ and $2 \mathrm{~min}$ at $72{ }^{\circ} \mathrm{C}$. The primers used to amplify the truncated mannanase genes were as follows: Man26A' (pJH7), 5'CGGGATCCCCTGCGGATGAAAGCATTG and 3'-CCGCTCGAGTTAATTGGAATCCTCATAATC; Man26A" (pJH8) 5'-CGGGATCCTCATGCATCAATGTGTTCA and 3'-CCGCTCGAGTTAATTGGAATCCTCATAATC. The amplified DNA was digested with BamHI and XhoI and ligated into BamHI/XhoI-restricted pET32a (Novagen) to generate $\mathrm{pJH} 7$ and $\mathrm{pJH} 8$.

E. coli $\mathrm{BL} 21(\mathrm{DE} 3)$ harbouring $\mathrm{pJH} 6$ or $\mathrm{pJH} 7$ was cultured to mid-exponential phase $\left(\mathrm{OD}_{600}=0.6\right)$ at $37^{\circ} \mathrm{C}$ in $\mathrm{LB}$ broth 
containing ampicillin $\left(50 \mu \mathrm{g} \mathrm{m}^{-1}\right)$. IPTG $(1 \mathrm{mM})$ was added and after a further $4 \mathrm{~h}$ incubation at $37^{\circ} \mathrm{C}$, cells were harvested, disrupted by ultrasonication in buffer containing $50 \mathrm{mM} \mathrm{NaH}_{2} \mathrm{PO}_{4}, 10 \mathrm{mM}$ Tris/HCl, pH 8.0, $100 \mathrm{mM} \mathrm{NaCl}$, and a cell-free extract was obtained by centrifugation $(10000 \mathrm{~g}, 20 \mathrm{~min})$. Hybrid proteins containing Man26 A' or Man26A" appended to thioredoxin were purified by nickel affinity chromatography on TALON resin (Clontech) according to the manufacturer's protocol. Bound fusion protein was cleared from the affinity resin during $2 \mathrm{~h}$ at room temperature using restriction-grade thrombin (Sigma) at a concentration of $0.5 \mathrm{U}$ (mg fusion protein $)^{-1}$ and the recommended buffer conditions (Novagen). Man26 $\mathrm{A}^{\prime}$ contained in the column eluant was dialysed against $10 \mathrm{mM}$ Tris $/ \mathrm{HCl}$, $\mathrm{pH} 8 \cdot 0$.

Assays and substrates. Standard enzyme assays were performed using $0.2 \%$ (final concentration) of the appropriate plant structural polysaccharide as the substrate in $0.5 \mathrm{ml}$ $50 \mathrm{mM}$ potassium phosphate, $12 \mathrm{mM}$ citric acid buffer, $\mathrm{pH} 6.5$ (PC buffer). The reaction was initiated by adding $50 \mu \mathrm{l}$ of an appropriate dilution of enzyme and the assay was allowed to proceed for $10 \mathrm{~min}$ at $60^{\circ} \mathrm{C}$. The reaction was terminated by adding $0.5 \mathrm{ml}$ dinitrosalicylic acid (Miller, 1959) and heating to $100{ }^{\circ} \mathrm{C}$ for $20 \mathrm{~min}$. Measurement of $A_{595}$ was used to quantify the amount of reducing sugar released from the various substrates. One unit of enzyme activity is the amount of enzyme that releases $1 \mu \mathrm{mol}$ reducing sugar $\min ^{-1}$ at $37^{\circ} \mathrm{C}$.

To identify the products released by Man26A, purified Man26A' was incubated with 0.66 mg manno-oligosaccharide $\mathrm{ml}^{-1}$ in PC buffer and at regular intervals the reactions were terminated by heating to $100{ }^{\circ} \mathrm{C}$ for $5 \mathrm{~min}$. The reaction products were subjected to HPLC analysis using a Dionex PA1 column eluted with $100 \mathrm{mM} \mathrm{NaOH}$ containing a $0-75 \mathrm{mM}$ gradient of sodium acetate. The sugars were detected with a pulsed amperometer and quantified by comparing the response produced by the various test samples with standard amounts of mannose and manno-oligosaccharides up to mannohexaose. There was a linear relationship between the amount of standard subjected to HPLC and the response of the pulsed amperometer. This applied for each standard evaluated.

Antiserum and Western blotting. Antiserum against purified Man26A was raised in Dutch rabbits. Initial injections of antigen $(200 \mu \mathrm{g})$ in Freund's complete adjuvant were administered via intramuscular and subcutaneous routes; subsequent doses, mixed with incomplete adjuvant, were given subcutaneously at $21 \mathrm{~d}$ intervals. Western blots were carried out according to the protocol recommended for the Enhanced Chemiluminescence detection system (ECL; Amersham).

Polysaccharide-binding studies. Binding of recombinant enzymes to mannan was evaluated as described previously (Clarke et al., 1991), based on the method of Gilbert et al. (1990). A suitable volume of recombinant purified protein was incubated with $1 \mathrm{mg}$ ivory-nut mannan (made up to a volume of $1 \mathrm{ml}$ with $100 \mathrm{mM}$ Tris/ $\mathrm{HCl}$ buffer, $\mathrm{pH} 8 \cdot 0$, containing $150 \mathrm{mM} \mathrm{NaCl}$ ) for $1 \mathrm{~h}$ at $4{ }^{\circ} \mathrm{C}$ with constant mixing.

Gel retardation studies were performed using native gels containing a final concentration of $0 \cdot 1 \%(\mathrm{v} / \mathrm{v})$ soluble carob galactomannan. Gels contained $7 \cdot 5 \%(\mathrm{v} / \mathrm{v})$ acrylamide and were made up in $25 \mathrm{mM}$ Tris $/ \mathrm{HCl}$ buffer, $\mathrm{pH} 8 \cdot 3$, containing $250 \mathrm{mM}$ glycine. Duplicate gels were run on the same apparatus in tandem; one gel containing carob galactomannan, the other containing no polysaccharide. Gels were then subjected to Western analysis using anti-Man26A antiserum as probe. As the two gels had migrated at exactly the same speed, a direct comparison could be made to determine the extent of retardation.

\section{RESULTS}

\section{Isolation of manA}

A genomic library of C. thermocellum DNA was constructed in 2 ZAPII and screened for plaques expressing enzymes capable of degrading azo carob galactomannan. A single mannanase ${ }^{+}$phage was isolated after repeated screenings, the recombinant phage was purified to homogeneity and the clostridial DNA excised and rescued as a recombinant of pBluescript $\mathrm{SK}$ - which was designated pJH1. Restriction fragments of the insert contained in pJH1 were subcloned into pBluescript $\mathrm{SK}-$ and the ability of the resulting plasmids to direct the expression of a functional mannanase was evaluated. The position of the putative mannanase gene, $\operatorname{man} A$, was located between the multiple cloning site of $\mathrm{pJH} 1$ and the EcoRI restriction site (Fig. 1).

To establish whether manA was a single-copy gene, the $1 \mathrm{~kb}$ clostridial insert from pJH5 was used to probe $C$. thermocellum genomic DNA digested with a range of restriction endonucleases. The results of the subsequent Southern analysis (data not shown) were consistent with the view that $\operatorname{man} A$ was carried on a single contiguous fragment of DNA and was present in the C. thermocellum genome as a single copy.

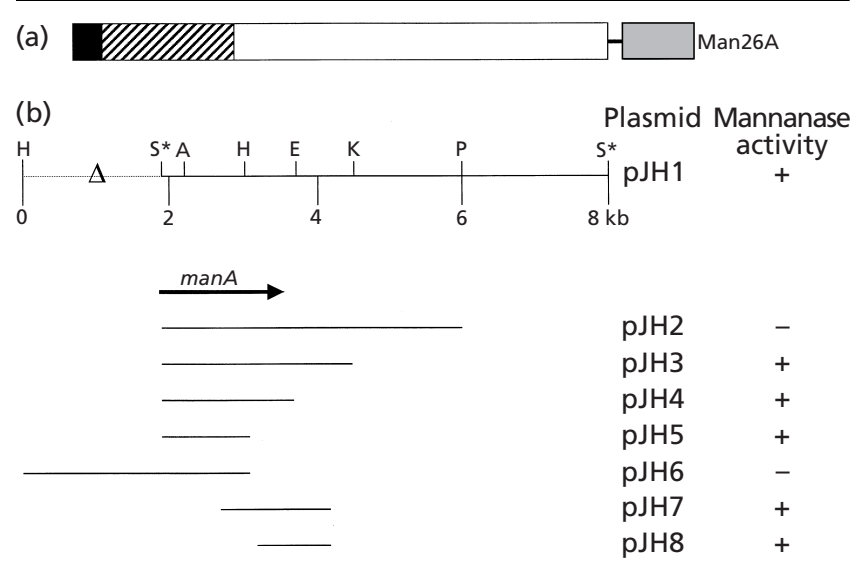

Fig. 1. Molecular architecture of Man26A and restriction map of recombinant plasmids containing Man26A. The molecular architecture of Man26A is shown in (a). The signal peptide (residues 1-24; solid bar), the mannan-binding domain (residues 25-165; hatched bar), the CD (residues 166-507; open bar), the P/T-rich 11-residue linker region (thin bar) and the dockerin domain (shaded bar) consisting of the C-terminal 70 residues are shown. The cleavage sites for the restriction enzymes Accl (A), HindIII (H), Kpnl (K) and Pstl (P) are shown in (b). The limits of the clostridial insert (partial Sau3a fragment) are indicated by $\mathrm{S}^{*}$. Plasmids $\mathrm{pJH} 2-\mathrm{pJH} 5$ were derived by subcloning restriction fragments from clostridial DNA in $\mathrm{pJH} 1$ into pBluescript SK-. pJH6 contains a HindIII clostridial fragment cloned into the low-copy-number vector pMTL6000. $\mathrm{pJH} 7$ and $\mathrm{pJH} 8$ were PCR products derived from $\mathrm{pJH} 1$ cloned into appropriate $\mathrm{pET}$ expression vectors. The capacity of the plasmids to express a functional mannanase is indicated. 


\section{Nucleotide sequence of C. thermocellum manA}

Sequencing of pJH1 in both strands revealed an incomplete ORF adjacent to the polylinker of pBluescript $\mathrm{SK}-$. Southern analysis identified a HindIII fragment, $3.0 \mathrm{~kb}$ in length, which would theoretically extend the ORF by $1.0 \mathrm{~kb}$. A partial DNA library of C. thermocellum genomic DNA digested with HindIII was constructed in the low-copy-number vector pMTL6000. Subsequent hybridization screening of the C. thermocellum genomic DNA library with the insert from pJH5 (containing incomplete $\operatorname{man} A$ ) resulted in the isolation of a single clone homologous to the probe DNA. This plasmid, designated pJH6, was sequenced on both strands and the manA ORF sequence was completed.

The manA ORF consisted of $1767 \mathrm{nt}$ encoding a polypeptide of 589 aa with a predicted molecular mass of $66816 \mathrm{Da}$. Upstream (8 nt) of the putative ATG start codon was the sequence GGAGG, which is the most frequently observed ribosome-binding site in C. thermocellum cellulases and hemicellulases and is similar to other Gram-positive bacterial Shine-Dalgarno motifs. Clostridial ORFs most frequently terminate with the stop codon TAA (Ochre); however, the manA ORF terminates with the TAG (amber) stop codon. The $3^{\prime}$ flanking region of $\operatorname{man} A$ did not contain any palindromic sequences resembling stem-loop structures, suggesting $\rho$-factor-dependent termination. The frequent use of the codons AGG (arginine), UUG (leucine) and CCG (proline) is indicative of C. thermocellum DNA and is a feature rarely found in mesophilic clostridia.

\section{Analysis of the translated amino acid sequence of C. thermocellum Man26A}

Inspection of the primary structure of Man26A from $C$. thermocellum revealed a modular architecture consisting of two distinct domains, the catalytic and dockerin domains, delineated by a linker region. The $\mathrm{N}$ terminal region contained a typical prokaryotic signal peptide with two lysine residues followed by a stretch of small hydrophobic residues capable of $\alpha$-helix formation. The predicted signal peptide cleavage site was between V23 and S24 which is unusual in that prokaryotic leader peptidases most frequently cleave after alanine residues (Perlman \& Halvorson, 1983), but a terminal serine residue has also been observed in the signal peptide of $C$. thermocellum CelC. The region extending between residues 166 and 507 of Man26A exhibited extensive sequence identity with the CDs of other family 26 mannanases (Fig. 1). Bolam et al. (1996) demonstrated that two glutamate residues act as the catalytic nucleophile and acid-base residues. It is widely believed that these residues are highly conserved within members of the same family and sequence homology suggested that E339 and E438 act as the acid-base and nucleophilic residues, respectively, in C. thermocellum Man26A.

Adjacent to the catalytic region of $C$. thermocellum Man26A is a duplicated region of 24 residues (Fig. 1).

\section{Table 1. Catalytic activity of Man26A derivatives}

Activity values are in mol product (mol enzyme $)^{-1} \mathrm{~s}^{-1}\left(k_{\text {cat }}\right) . K_{\mathrm{m}}$ values are in mg substrate $\mathrm{ml}^{-1}$.

\begin{tabular}{|lccccc|}
\hline \multirow{2}{*}{ Enzyme } & \multicolumn{2}{c}{ Carob galactomannan } & & \multicolumn{2}{c|}{ Ivory-nut mannan } \\
\cline { 2 - 3 } \cline { 5 - 6 } & Activity & $\boldsymbol{K}_{\mathrm{m}}$ & & Activity & $\boldsymbol{K}_{\mathrm{m}}$ \\
\cline { 6 - 7 } Man26A" & 5013 & $10 \cdot 1$ & & 250 & $3 \cdot 5$ \\
Man26A' & 4632 & $10 \cdot 3$ & & 114 & $7 \cdot 1$ \\
\hline
\end{tabular}

This sequence of 71 aa exhibited strong homology with the reiterated conserved region of other C. thermocellum cellulosomal enzymes, which is termed the dockerin and mediates formation of the cellulosome by binding catalytic subunits to the cohesin domains of CipA (Tokatlidis et al., 1991). The presence of a dockerin sequence indicated the potential of C. thermocellum Man26A to associate with the cellulosome scaffolding protein, CipA (Bayer et al., 1994).

\section{Biochemical characterization}

The region of Man26A extending from residue 166 to 507, which exhibited the strongest homology with family 26 mannanase CDs, was hyperexpressed in E. coli using the pET system (Novagen). This generated a thioredoxin-Man26A' fusion protein which was purified using nickel affinity chromatography. Man26A' was cleaved from the thioredoxin by thrombin cleavage.

The substrate specificity of C. thermocellum Man26A was determined by incubating purified Man26A' with a range of substrates. The enzyme was active against carob galactomannan, ivory-nut Man26A' and locustbean galactomannan. No reducing sugar was detected when purified Man26A' was incubated with a range of other polysaccharides, including cellulose, soluble xylan, galactan, pectin, laminarin and lichenan. These data show that $C$. thermocellum Man26A is a mannanase with narrow substrate specificity: the enzyme does not hydrolyse other polysaccharides and specifically cleaves the $\beta$ - $(1,4)$-glycosidic linkages between mannopyranosyl residues. Kinetic parameters for C. thermocellum Man26A' are presented in Table 1.

Man26A' displayed thermostable properties, exhibiting a half-life of $30 \mathrm{~min}$ at $74^{\circ} \mathrm{C}$. An apparent temperature optimum of $65^{\circ} \mathrm{C}$ was noted with Man26A' retaining significant activity over a wide temperature range. Activity decreased sharply above $70^{\circ} \mathrm{C}$ defining an upper limit to the thermotolerance of C. thermocellum Man26A. The $\mathrm{pH}$ activity profile of C. thermocellum Man26A' displayed apparently optimal activity at $\mathrm{pH} 6 \cdot 5$. No activity was observed at $\mathrm{pH} 3$ or 10 .

To establish whether C. thermocellum Man26A' exhibited maximum activity against polymeric mannan molecules, the capacity of the enzyme to hydrolyse a range of water-soluble manno-oligosaccharides was 
(a)

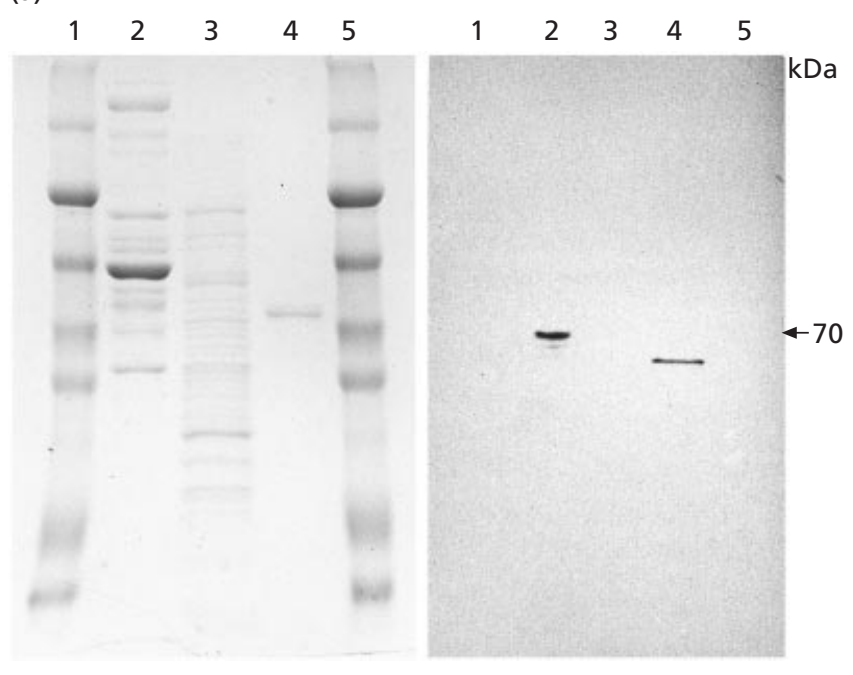

Fig. 2. Production of Man26A by $C$. thermocellum. (a) Coomassie blue-stained SDS-PAGE gel; (b) an identical gel subjected to Western analysis using antibodies raised against Man26A'. Lanes: 1 and 5, pre-stained markers (Sigma); 2, C. thermocellum cellulosomal proteins; 3 , cell-free extract of E. coli BL21(DE3) containing no plasmid; 4, purified Man26A'. The $70 \mathrm{kDa}$ cellulosomal protein that cross-reacted with antiMan26A' antibodies is indicated.

evaluated. The products released were analysed using Dionex HPLC. The relative time taken for $50 \%$ cleavage of the substrate of Man26 $\mathrm{A}^{\prime}$ against mannotriose, mannotetraose, mannopentaose and mannohexaose were $50,6 \cdot 7,3 \cdot 6$ and 1 , respectively, demonstrating that

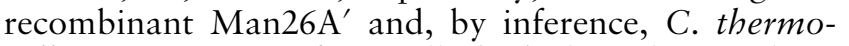
cellum Man26A preferentially hydrolyses larger oligosaccharides.

\section{Production of Man26A by C. thermocellum}

To determine whether Man26A is produced by $C$. thermocellum as a component of the aggregated cellulosome complex, cellulosome was purified by affinity chromatography (Morag et al., 1992) and subjected to Western analysis, using anti-Man26 $\mathrm{A}^{\prime}$ antiserum as probe. The use of antiserum raised against Man26A' (excluding dockerin) precluded any cross-reactivity with other dockerin-containing components of the cellulosome including CipA.

A single immunoreactive band with an apparent molecular mass of $70 \mathrm{kDa}$ was detected in the cellulosomal proteins purified from C. thermocellum (Fig. 2). The size of the immunoreactive protein was in good agreement with the size of Man26A calculated from the deduced amino acid sequence. The duplicated 24-residue region at the $\mathrm{C}$ terminus therefore appeared to be a functional dockerin domain facilitating attachment of the enzyme to CipA.

\section{Polysaccharide-binding domain of Man26A}

Sequence alignment revealed that the $\mathrm{N}$-terminal region of Man26A, extending from residue 34 to 165 displayed homology with ManA, ManB and ManC from the anaerobic fungus Piromyces equi (Fig. 3). The same region also displayed some homology with domains of unknown function present in xylanases XYNB and XYNC of Pseudomonas fluorescens subsp. cellulosa, a mannanase ManA from Rhodothermus marinus and an isomaltodextranase from Arthrobacter globiformis.

To investigate the possible function of this N-terminal region of Man26A, a second variant of Man26A containing the $\mathrm{N}$-terminal segment of 130 residues and the $\mathrm{CD}$ was produced using the expression vector pET32a. The purified protein was termed Man26A".

Comparative activities of Man26A' and Man26A" against soluble and insoluble mannan demonstrated a twofold decrease in activity of Man26A" against insoluble substrates when compared to Man26 $\mathrm{A}^{\prime}$. This suggested a role for the $\mathrm{N}$-terminal domain of $C$. thermocellum Man26A in enhancing activity against insoluble substrates. The reduction in activity against insoluble substrates of Man26A' compared to Man26A" was attributed to the absence of the $\mathrm{N}$-terminal domain
C. thermocellum ManA $P$. equi ManB P. equi ManA P. equi ManC

\footnotetext{
C. thermocellum ManA $P$. equi ManB

$P$. equi ManA

$P$. equi ManC

C. thermocellum ManA P. equi ManB P. equi ManA

P. equi ManC

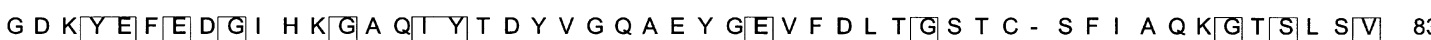
KVYY Y A E N GKLD GVTVYK . . . . . . SDLTGF S G TGYVGRFENPGN SVTV 62 K V Y Y E A E D G K L N G I T V F K - - . - . - - E L S G F S G K G Y V GR F E N P G N S V T V 61 K V I Y Y E A E N G K L D G G S K Y N N - . . - . - . E L Q G G Y S G T G Y V GR F E S A G N S V T V

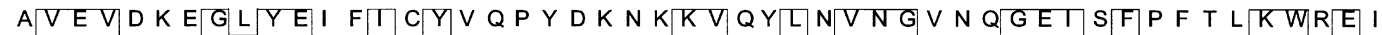
TVE V P QT GM Y D L TI V Y CA - - NMGQK I NS L T V N G Q S A G D I T F T E NT K F E D L

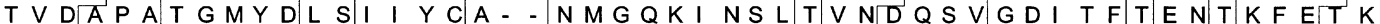
T V E V S Q T G M Y D M S I I Y C G - N M G Q I N S L K I N N K N S G D I T F P E N S S F E E L

133

110

109

109
}

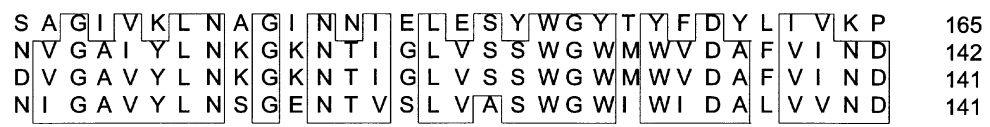

Fig. 3. Alignment of the Clostridium Man26A N-terminal domain with ManA, ManB and ManC from Piromyces equi. Amino acids that are identical or homologous in the different proteins are boxed and the position of the amino acids at the end of each line of each primary sequence is indicated. The SWISS-PROT accession numbers for the Piromyces mannanases are P55296 (ManA), P55297 (ManB) and P55298 (ManC). 


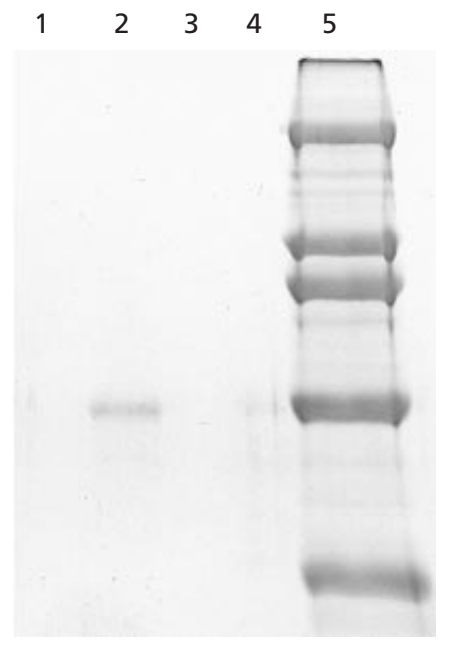

Fig. 4. Binding assay of Man26A' and Man26A" against insoluble mannan. Man26 $A^{\prime}$ and Man26 $A^{\prime \prime}$ were incubated with ivory-nut mannan, which was washed several times, and bound protein was eluted with $10 \%(w / v)$ SDS and boiling for 5 min. The last wash of the polysaccharide incubated with Man26A" (lane 1) and Man26A' (lane 3), and the protein eluted with SDS from mannan which had been incubated with Man26A" (lane 2) and Man26A' (lane 4) was subjected to SDSPAGE. Lane 5, high-molecular-mass standards (Sigma).

in Man26A'. This property has been reported previously as characteristic of binding domains (Coutinho et al., 1993; Tomme et al., 1988; McGavin \& Forsberg, 1989).

To confirm the polysaccharide-binding properties of the $\mathrm{N}$-terminal domain of Man26A, binding assays were performed with insoluble mannan (Fig. 4). Purified Man26A" bound to insoluble mannan, but Man26A' did not. To further describe the binding properties of the $\mathrm{N}$-terminal domain of Man26A, the capacity of the protein to bind insoluble cellulose (Avicel and acidswollen cellulose) and xylan was also evaluated. The polypeptide bound both forms of cellulose weakly, but exhibited no affinity for insoluble xylan (data not shown). To evaluate the capacity of Man26A" to bind soluble polysaccharides, gel retardation assays were performed using soluble polysaccharides incorporated into non-denaturing polyacrylamide gels. The presence of soluble mannan caused a small retardation of Man26A" but not Man26A' (Fig. 5). Neither protein was retarded by soluble wheat or rye arabinoxylan, barley $\beta$-glucan, hydroxyethyl cellulose, amylose, $\alpha-1,5-$ arabinan, $\beta$-1,4-galactan or polygalacturonic acid (data not shown). Although these data infer that Man26A" bound very weakly to soluble mannan (carob galactomannan), this interpretation must be viewed with some caution as the galactose substituents could reduce the affinity of the protein for the mannan backbone and thus the results may underestimate the true affinity of the polypeptide for unsubstituted mannan. In summary, these data suggest that the region of Man26A extending from residue 34 to 165 functions primarily as a weak mannan-binding domain, although it does exhibit some capacity to bind insoluble cellulose.

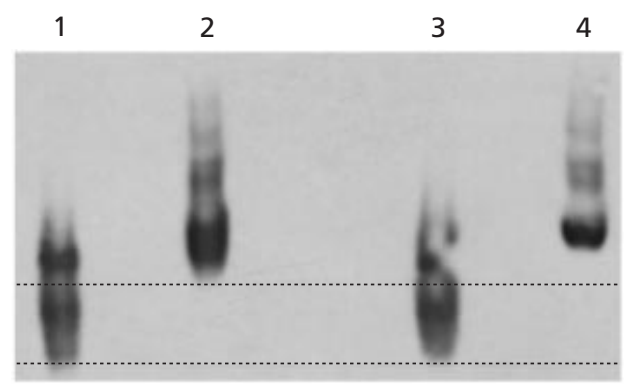

Fig. 5. Affinity gel electrophoresis assay of truncated forms of C. thermocellum Man26A. Man26A' (lanes 1 and 3) and Man26A" (lanes 2 and 4) were electrophoresed under nondenaturing conditions in gels containing no ligand (lanes 1 and 2) and a gel containing carob galactomannan (lanes 3 and 4). The speed of electrophoresis of the two gels was identical. The dashed lines represent the horizontal plane.

\section{DISCUSSION}

Data presented in this paper show that Man26A is the first bacterial mannanase to be identified as a component of a high-molecular-mass prokaryotic cellulase/ hemicellulase complex. C. thermocellum cannot utilize xylan, mannan or their constituent monosaccharides (Wiegel et al., 1985), although it has been well documented that this bacterium secretes a range of xylandegrading enzymes (Grépinet et al., 1988; Fontes et al., 1995; Hayashi et al., 1997), and data presented here show that C. thermocellum secretes a mannan-degrading enzyme. The apparent paradox of expending cellular energy on synthesis of xylan and mannan-degrading enzymes can be explained by these hemicellulases contributing to the degradation of the mannan and xylan matrix surrounding cellulose. It is thought that this breakdown of hemicellulose facilitates greater accessibility for the cellulosome to the cellulose microfibrils.

The identification of a domain that binds weakly to mannan in the cellulosomal enzyme Man26A is intriguing. Although the domain appears to cause a modest increase in the catalytic activity of the mannanase against recalcitrant insoluble substrates, it may also play a general role in providing the cellulosome with a receptor for mannan. Cellulosome attachment to cellulose microfibrils is mediated via the family IIIa CBD of CipA (Morag et al., 1995). Therefore, cellulosomal enzymes containing discrete CBDs would at first glance appear superfluous. However, several C. thermocellum cellulases and xylanases which are components of the cellulosome, also contain discrete CBDs (reviewed by Bayer et al., 1998; Hazlewood \& Gilbert, 1997). It has been proposed that they may serve to increase further the affinity of the cellulosome for cellulose by the accumulative effect of these $\mathrm{CBDs}$ and $\mathrm{CipA}_{\mathrm{CBD}}$, or play a more direct role in the action of specific catalytic subunits within the complex. The cellulosome displays low affinity for ivory-nut mannan (results not shown). Whether this is attributable to Man26A, CipA $\mathrm{CBD}_{\text {or }}$ both remains unclear at this time (Tomme et al., 1995). 
Interestingly, the lack of a linker region delineating the weak mannan-binding region and the CD of Man26A would appear to disagree with the accepted dogma for the evolution of microbial glycosyl hydrolase architecture. The majority of functional domains of modular glycosyl hydrolases are separated by linker regions rich in hydroxy amino acids, including serine, threonine and proline (Ferreira et al., 1990). It has been suggested that recombination between the DNA encoding these linker sequences has led to the evolution of multidomain glycosyl hydrolases (Ferreira et al., 1990). The lack of a linker region delineating the binding and CDs of Man26A is unusual. It is possible that the mannanbinding domain was acquired by $C$. thermocellum through horizontal gene transfer and was fused to a bacterial mannanase gene in a subsequent recombination event. Alternatively, the mannan-binding domain/mannanase CD may be more closely related to the anaerobic fungal mannanases and a single gene encoding these two domains may have been imported directly into C. thermocellum. The absence of a linker sequence between the mannan-binding domain and $\mathrm{CD}$ of Man26A questions the importance of these regions in modular glycosyl hydrolases. In previous studies, linkerless derivatives of $P$. fluorescens subsp. cellulosa XYLA and Trichoderma reesei cellobiohydrolase I retained the ability to hydrolyse soluble substrates and to bind to cellulose when compared to their respective full-length enzymes (Ferreira et al., 1990; Srisodsuk et al., 1993). These results inferred that the CD and CBD of these enzymes do not need to be separated by linker sequences to retain function. In contrast, removal of linker sequences from Cellulomonas fimi endoglucanase A reduced activity of the enzyme against soluble and highly crystalline substrates and affected its desorption from cellulose (Shen et al., 1991). This was attributed to the steric hindrance generated by the close proximity of the CBD to the CD. The identification of a glycosyl hydrolase not delineated by a linker region, but which still comprises discrete functional domains, demonstrates that linker regions are not always essential for the discrete domains in glycosyl hydrolases to retain their proper function. In nature, two glycosyl hydrolases, endoglucanase E4 and CelG from Thermomonospora fusca and Clostridium cellulolyticum, respectively, were shown to lack a linker sequence between the $\mathrm{CD}$ and the type IIIc CBD, which exhibited very weak affinity for cellulose (Irwin et al., 1998; Gal et al., 1997). Resolution of the three-dimensional structure of a truncated form of E4 showed that the type IIIc CBD extended the substratebinding cleft of the CD such that the enzyme could accommodate 12 glucose residues. It was proposed that the type IIIc CBD fed cellulose chains into the active site of the enzyme and that this played a pivotal role in the hydrolysis of recalcitrant crystalline substrates (Sakon et al., 1997), and explained the processive mode of action of the enzyme. Although it is tempting to speculate that the mannan-binding domain in Man26A plays a similar role to the type IIIc CBD in endoglucanases E4 and CelG, we believe that this is unlikely as there is no apparent loss in activity against soluble substrates when this domain is removed and only a twofold reduction in catalytic rate against crystalline mannan. In addition,

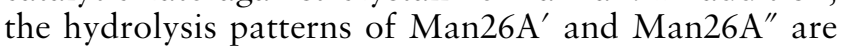
not substantially different.

\section{REFERENCES}

Bayer, E. A., Morag, E. \& Lamed, R. (1994). The cellulosome - a treasure trove for biotechnology. Trends Biotechnol 12, 379-386.

Bayer, E. A., Shimon, L. J. W., Shoham, Y. \& Lamed, R. (1998). Cellulosomes - structure and ultrastructure. J Struct Biol 124, 221-234.

Black, G. W., Hazlewood, G. P., Xue, G. P., Orpin, C. R. \& Gilbert, H. J. (1994). Xylanase B from Neocallimastix patriciarum contains a non-catalytic 465-residue linker sequence comprised of 57 repeats of an octapeptide. Biochem J 299, 381-387.

Bolam, D. N., Hughes, N., Virden, R., Lakey, J. H., Hazlewood, G. P., Henrissat, B., Braithwaite, K. L. \& Gilbert, H. J. (1996). Mannanase A from Pseudomonas fluorescens subsp. cellulosa is a retaining glycosyl hydrolase in which E212 and E320 are the putative catalytic residues. Biochemistry 35, 16195-16204.

Clarke, J. H., Laurie, J. I., Gilbert, H. J. \& Hazlewood, G. P. (1991). Multiple xylanases of Cellulomonas fimi are encoded by distinct genes. FEMS Microbiol Lett 83, 305-310.

Coutinho, J. B., Gilkes, N. R., Kilburn, D. G., Warren, R. A. J. \& Miller, R. C., Jr (1993). The nature of the cellulose-binding domain affects the activities of a bacterial endoglucanase on different forms of cellulose. FEMS Microbiol Lett 113, 211-218.

Ferreira, L. M. A., Durrant, A. J., Hall, J., Hazlewood, G. P. \& Gilbert, H. J. (1990). Spatial separation of protein domains is not necessary for catalytic activity or substrate binding in a xylanase. Biochem J 269, 261-264.

Fontes, C. M. G. A., Hazlewood, G. P., Morag, E., Hall, J., Hirst, B. H. \& Gilbert, H. J. (1995). Evidence for a general role for noncatalytic thermostabilizing domains in zylanases from thermophilic bacteria. Biochem J 307, 151-158.

Gal, L., Gaudin, C., Belaich, A., Pagès, S., Tardif, C. \& Belaich, J.-P. (1997). CelG from Clostridium cellulolyticum: a multidomain endoglucanase acting efficiently on crystalline cellulose. $J$ Bacteriol 179, 6596-6601.

Gilbert, H. J., Jenkins, G., Sullivan, D. A. \& Hall, J. (1987). Evidence for multiple carboxymethylcellulase genes in Pseudomonas fluorescens subsp. cellulosa. Mol Gen Genet 210, 551-556.

Gilbert, H. J., Hall, J., Hazlewood, G. P. \& Ferreira, L. M. A. (1990). The N-terminal region of an endoglucanase from Pseudomonas fluorescens subsp. cellulosa constitutes a cellulose binding domain that is distinct from the catalytic centre. Mol Microbiol 4, 759-767.

Grépinet, O., Chebrou, M.-C. \& Béguin, P. (1988). Nucleotide sequence and deletion analysis of the xylanase gene $(x y n Z)$ of Clostridium thermocellum. J Bacteriol 170, 4582-4588.

Hayashi, H., Takagi, K.-I., Fukumura, M., Kimura, T., Karita, S., Sakka, K. \& Ohmiya, K. (1997). Sequence of $x y n C$ and properties of XynC, a major component of the Clostridium thermocellum cellulosome. J Bacteriol 179, 4246-4253.

Hazlewood, G. P. \& Gilbert, H. J. (1997). Structure and function analysis of Pseudomonas fluorescens subsp. cellulosa plant cell wall hydrolases. Prog Nucleic Acid Res Mol Biol 61, 211-241.

Irwin, D., Shin, D.-H., Zhang, S., Barr, B. K., Sakon, J., Karplus, P. A. \& Wilson, D. D. (1998). Roles of the catalytic domain and two cellulose binding domains of Thermomonospora fusca E4 in cellulose hydrolysis. J Bacteriol 180, 1709-1714. 
Kemp, P., Lander, D. J. \& Orpin, C. G. (1984). The lipids of the anaerobic rumen fungus Piromyces communis. J Gen Microbiol 130, 27-37.

Lamed, R. \& Bayer, E. A. (1988). The cellulosome of Clostridium thermocellum. Adv Appl Microbiol 33, 1-46.

McGavin, M. \& Forsberg, C. W. (1989). Catalytic and substratebinding domains of endoglucanase-2 from Bacteroides succinogenes. J Bacteriol 171, 3310-3315.

Miller, G. L. (1959). Use of dinitrosalicylic acid reagent for determination of reducing sugar. Anal Chem 31, 426-428.

Morag, E., Bayer, E. A. \& Lamed, R. (1992). Affinity digestion for the near total recovery of purified cellulosome from Clostridium thermocellum. Enzyme Microb Technol 14, 289-292.

Morag, E., Lapidot, A., Govorko, D., Lamed, R., Wilchek, M., Bayer, E. A. \& Shoham, Y. (1995). Expression, purification and characterization of the cellulose-binding domain of the scaffoldin subunit from the cellulosome of Clostridium thermocellum. Appl Environ Microbiol 61, 1980-1986.

Perlman, D. \& Halvorson, H. O. (1983). A putative signal peptidase site and sequence on eukaryotic and prokaryoptic signal peptides. J Mol Biol 167, 391-409.

Puls, J. \& Schuseil, J. (1993). Chemistry of hemicelluloses: relationship between hemicelluose structure and enzymes required for hydrolysis. In Hemicellulase and Hemicellulases, pp. 1-27. Edited by M. P. Coughlan \& G. P. Hazlewood. London: Portland Press.

Romaniec, M. P. M., Clarke, N. \& Hazlewood, G. P. (1987). Molecular cloning of Clostridium thermocellum DNA and the expression of further novel endo- $\beta$-1,4-glucanase genes in Escherichia coli. J Gen Microbiol 133, 1297-1307.

Sakon, J., Irwin, D., Wilson, D. B. \& Karplus, P. A. (1997). Structure and mechanism of endo/exocellulase E4 from Thermomonospora fusca. Nature Struct Biol 4, 810-818.

Shen, H., Schmuck, M., Pilz, I., Gilkes, N. R., Kilburn, D. G. \& Miller, R. C., Jr (1991). Deletion of the linker connecting the catalytic and cellulose binding domains of endoglucanase A (CENA) of Cellulomonas fimi alter its conformation and catalytic activity. J Biol Chem 266, 11335-11340.

Srisodsuk, M., Reinikainen, T., Penttila, M. \& Teeri, T. (1993). Role of the interdomain linker peptide of Trichoderma reesei cellobiohydrolase-I in its interaction with crystalline cellulose. $J$ Biol Chem 268, 20756-20761.

Tokatlidis, K., Salamitou, S., Béguin, P., Dhurjati, P. \& Aubert, J. P. (1991). Interaction of the duplicated segment carried by Clostridium thermocellum cellulases with cellulosome components. FEBS Lett 291, 185-188.

Tomme, P., Vantilbeurgh, H., Pettersson, G., Vandamme, J., Vandekerckhove, J., Knowles, J., Teeri, T. \& Claeyssens, M. (1988). Studies of the cellulolytic system of Trichoderma reesei QM-9414 - analysis of domain function in two cellobiohydrolases by limited proteolysis. Eur J Biochem 170, 575-581.

Tomme, P., Warren, R. A. J. \& Gilkes, N. R. (1995). Cellulose hydrolysis by bacteria and fungi. Adv Microb Physiol 37, 1-77.

Tormo, J., Lamed, R., Chirino, A. J., Morag, E., Bayer, E. A., Shoham, Y. \& Steitz, T. A. (1996). Crystal structure of a bacterial family-III cellulose binding domain, a general mechanism for attachment to cellulose. EMBO J 15, 5739-5751.

Wiegel, J., Mothershed, C. P. \& Puls, J. (1985). Differences in xylan degradation by various noncellulolytic thermophilic anaerobes and Clostridium thermocellum. Appl Environ Microbiol 49, 656-659.

Received 21 April 1999; revised 6 July 1999; accepted 22 July 1999. 